\title{
Hacia una Revista moderna
}

\section{Towards a Modern Journal}

La Revista Chilena de Cirugía es el órgano oficial de la Sociedad de Cirujanos de Chile. En este editorial daremos cuenta de algunos cambios que tienen como objetivo optimizar su presentación y contenido, además de aumentar su visibilidad en el ámbito mundial, intentando adecuarla a los estándares internacionales.

\section{Aspectos generales}

En el diseño general, se ha incorporado el temario en la portada, se han modificado las Instrucciones a los Autores según pautas universales, se ha separado el cuerpo estable de la revista de las autoridades de la Sociedad y últimamente se ha incorporado el índice en inglés.

En el formato de los artículos, ha sido incorporado el título en inglés, la traducción de los resúmenes por un médico con experiencia en el tema artículos médicos y la inclusión de la filiación de cada autor, así como fechas de recepción y aceptación de trabajos. Se han uniformado las referencias bibliográficas según conceptos universalmente aceptados.

\section{Consejo Editorial}

El Consejo Editorial tiene dos finalidades en las revistas médicas modernas, el primero es ayudar al editor científico en la línea gruesa editorial y de los contenidos. El segundo fin de este cuerpo colegiado es dar, mediante su nombre, peso intelectual y (o) cientifico a la publicación. Hemos modificado el nuestro de forma de conseguir estos objetivos; para lo citado en segundo término ha sido incorporado un número significativo de personalidades de la cirugía mundial.

La función editorial es central. El editor es quien recibe las colaboraciones y, una vez corroborado que cumplen con las normas de la revista, organiza la revisión y toma las decisiones de aceptación.

Además el editor, con la colaboración del coeditor y el C. Editorial, debe en ocasiones corregir los "manuscritos", lo que puede implicar, sin alterar el contenido fundamental que los autores quieren comunicar, hacer cambios importantes en el texto.

\section{Evaluación por pares}

En el mundo actual de las publicaciones cientificas, se considera fundamental la evaluación o revisión por pares de los artículos recibidos. Deben ser pares con conocimiento del tema a evaluar, y en lo posible independientes del comité editorial.

Aquí se introduce una importante variación respecto a lo tradicional en nuestra revista, en la que lo usual era precisamente lo contrario, es decir, que los revisores eran sólo aquellos pertenecientes a dicho comité. Se considera que la evaluación por parte del universo invisible al que pertenece el autor mejora la calidad del material publicado. Sin embargo, los evaluadores deben aconsejar y no decidir, quienes deciden qué se publica o qué se rechaza son el editor o el consejo de editores, los que deben estar capacitados para identificar la importancia y calidad de los artículos y de las modificaciones propuestas.

Entre nosotros, en lo referente a la revisión de los artículos enviados para su publicación, desde hace varios años ha sido incorporada la revisión por pares, esto es, como se menciona más arriba, no sólo por miembros del Comité Editorial sino que preferentemente por especialistas calificados externos al mismo, que forman parte activa de la disciplina a que el texto se refiere. La revisión por pares es un elemento moderno exigido en la actualidad en todas las publicaciones serias por la confiabilidad que otorga al producto final a publicar. 


\title{
Manejo electrónico del material
}

Asimismo, gradualmente se ha ido incorporando el manejo electrónico del material, así como la comunicación, también por esta vía, entre los autores y el comité editorial, los revisores y la Editorial. Por ello y para ello, en el formato de los artículos se incluye ahora la dirección postal y electrónica.

\section{Contenidos}

En lo que se refiere a los contenidos, hace algún tiempo pasamos por un período durante el cual disponíamos de poco material publicable, por lo que editamos varios números con menos páginas de lo usual. La alternativa era disminuir los números a 4 anuales, pero ello ponía en riesgo nuestra permanencia en SciELO. En la actualidad, disponemos de más material por lo que se ha vuelto a publicar revistas con 90 a 100 páginas.

No puedo calificar si la calidad de los contenidos ha mejorado, pero creo que ella es sólo el producto de quiénes somos y que representamos.

\section{Visibilidad internacional}

Internet es muy importante para la publicación de revistas, las que pueden tener una versión impresa y otra electrónica idénticas, versiones diferentes, o sólo una versión electrónica. Consideramos en el momento actual que la revista en el formato de papel que conocemos debe permanecer. Sin embargo, también es importante que además tenga una amplia difusión en las bases electrónicas, ya que ello claramente la internacionaliza y la hace accesible, literalmente, a todo el mundo.

Hemos incorporado la revista en nuestra página web, en la que creamos un estupendo motor de búsqueda que con un clic nos muestra lo publicado por tema y autor.

También se encuentra en LILACS, en la base de bibliotecas electrónicas de la Universidad de Chile (SISIB), en IMBIOMED (trascendente base mexicana de difusión mundial), en SciELO (exigente base de datos electrónica internacional manejada en Chile por Conicyt).

En los últimos meses hemos sido contactados por Google Academic y hemos llegado a un acuerdo que permite, en forma gratuita para la Sociedad, digitalizar e indexar en Google los últimos 17 años de la revista.

En el mismo ámbito, en los últimos seis meses, y luego de la asistencia del editor a un curso de ISI, hemos estado enviando los últimos números a la casa matriz de la entidad en USA -ISI Web of Knowledge de Thompson- para ser considerados para su indexación como revista ISI. Los cirujanos que se mueven en el ámbito científico y académico conocen que significa para nosotros ser aceptados. A modo de ejemplo: de más de 50 títulos médicos que se publican en el país sólo 3 son ISI. Para algunos, en el ámbito académico de las publicaciones científicas, sólo tienen existencia real aquellas revistas que pertenecen a dicho índice, las demás no existen.

Con profunda satisfacción podemos comunicar hoy que nuestra revista ha sido aceptada, por lo que desde enero del presente año somos una "revista ISI".

Todo lo anterior se traduce en mejorar y aumentar nuestra visibilidad internacional. Asi, hoy podemos apreciar cómo, cada vez con frecuencia mayor, están apareciendo en la revista artículos y comunicaciones de nuestros pares del resto de América y Europa. Por supuesto ello también implica que lo que nosotros producimos es leído en otros lugares de esta aldea global, siendo nuestras experiencias conocidas y citadas en otros lugares del mundo.

Con el transcurrir del tiempo es posible que la publicación electrónica reemplace en gran medida a la de papel. Creo que para nosotros ese momento aún no ha llegado.

\author{
Prof. Dr. Julio Yarmuch G. \\ Editor Jefe \\ Revista Chilena de Cirugía
}

